Article

\title{
Forecasting the Impacts of Prescribed Fires for Dynamic Air Quality Management
}

\author{
M. Talat Odman ${ }^{1, *(1)}$, Ran Huang ${ }^{1}$ (D), Aditya A. Pophale ${ }^{1}$, Rushabh D. Sakhpara ${ }^{1}$, \\ Yongtao Hu ${ }^{1}$, Armistead G. Russell ${ }^{1}$ and Michael E. Chang ${ }^{2}$ (D) \\ 1 School of Civil and Environmental Engineering, Georgia Institute of Technology, Atlanta, GA 30332, USA; \\ ranhuang2014@gatech.edu (R.H.); aditya.pophale@gmail.com (A.A.P.); \\ rushabh.sakhpara@gmail.com (R.D.S.); yongtao.hu@gmail.com (Y.H.); ted.russell@gatech.edu (A.G.R.) \\ 2 Brook Byers Institute for Sustainable Systems, Georgia Institute of Technology, Atlanta, GA 30332, USA; \\ chang@gatech.edu \\ * Correspondence: odman@gatech.edu; Tel.: +1-404-894-2783
}

Received: 21 April 2018; Accepted: 31 May 2018; Published: 8 June 2018

\begin{abstract}
Prescribed burning (PB) is practiced throughout the USA, most extensively in the southeast, for the purpose of maintaining and improving the ecosystem and reducing wildfire risk. However, $\mathrm{PB}$ emissions contribute significantly to trace gas and particulate matter loads in the atmosphere. In places where air quality is already stressed by other anthropogenic emissions, PB can lead to major health and environmental problems. We developed a PB impact forecasting system to facilitate the dynamic management of air quality by modulating PB activity. In our system, a new decision tree model predicts burn activity based on the weather forecast and historic burning patterns. Emission estimates for the forecast burn activity are input into an air quality model, and simulations are performed to forecast the air quality impacts of the burns on trace gas and particulate matter concentrations. An evaluation of the forecasts for two consecutive burn seasons (2015 and 2016) showed that the modeling system has promising forecasting skills that can be further improved with refinements in burn area and plume rise estimates. Since 2017, air quality and burn impact forecasts are being produced daily with the ultimate goal of incorporating them into the management of PB operations.
\end{abstract}

Keywords: burn activity forecasting; burn area; fire emissions; classification and regression tree (CART); community multiscale air quality (CMAQ) model; decoupled direct method (DDM); forecast evaluation; $\mathrm{PM}_{2.5}$; prescribed burning; satellite detection

\section{Introduction}

Prescribed burning (PB) is the intentional, controlled burning of dead and live vegetation for agricultural, land clearing, or silvicultural purposes, or simply to reduce the wildfire risk [1]. Here, we are mostly interested in the PB of forested lands. Forests in Southeastern USA contain many fire-adapted tree species that need fire to survive [2]. Fire restores nutrients to the soil, kills invasive species, controls insects and disease, improves wildlife habitat, and reduces the accumulation of debris on the forest floor. If left untreated, accumulated debris increases the chances of catastrophic wildfires that not only destroy forests but cause loss of life and property [3]. Due to these benefits, land managers prefer prescribed fire over other alternatives. In Southeastern USA, more than 2 million ha are treated with prescribed fire each year, and Georgia is one of the leading states in PB with nearly 550,000 ha year ${ }^{-1}$ [4].

Smoke generated by prescribed fires can travel long distances and contribute to air quality problems in urban areas [5] and threaten human health [6,7]. With all the other sources being controlled 
heavily, prescribed fire has become the leading source of $\mathrm{PM}_{2.5}$ (particulate matter with an aerodynamic diameter smaller than $2.5 \mu \mathrm{m}$ ) in Southeastern USA, with $250 \mathrm{Gg}_{\text {year }}{ }^{-1}$ or $27 \%$ of the total emissions [8]. Wildfires are expected to increase in the future as a result of the changing climate [9,10]. We can expect a similar increase in the use of prescribed fire as a measure to prevent wildfires. This will further increase the burden of prescribed fire emissions on the air quality of the region.

Accepting PB as a desirable forestry practice but understanding its negative impacts on air quality brings the challenge of finding the best compromise between forestry and air quality interests. Static solutions, such as imposing a burn ban during certain times of the year when air quality is typically burdened (e.g., ozone season) may be too restrictive for forestry interests. Conversely, conducting burns during certain times of the year (e.g., growing season) without regard for air quality may be inadequate to air quality interests. A more acceptable solution for both interests may be found through dynamic air quality management (DAQM), a paradigm where new information is incorporated in decision-making as soon as it becomes available. DAQM can involve the adaptation to new data that becomes available, such as air pollution measurements or new emissions estimates, or changes in activity patterns. For example, instead of operating with the same official emissions inventory for several years, updated inventories could be used for interim years. Perhaps the most agile form of DAQM is the one based on forecasting. PB activity is closely related to weather, especially to rain and winds [11]. Therefore, the upcoming demand for burning can be predicted from the weather forecast. Similarly, air quality can be, and is being, predicted using the weather forecast. Knowledge of the day-to-day fluctuations in prescribed fire emissions according to burn demand predictions can significantly improve the accuracy of air quality forecasts. A reliable forecasting system, including weather, burn activity, air quality and impacts of PB on air quality, could lead to cohesive PB and air quality management strategies. If the impacts of different emission sources are forecast, then appropriate control measures can be taken to reduce those impacts and achieve better air quality [12]. PB is one emission source that can be controlled more easily than other sources since burn/no-burn decisions are made every day. Through the permitting systems already in place in several Southeastern states, burns can be restricted on imminent poor air quality days and encouraged when meteorological conditions are more favorable. The application of DAQM in this manner may lead to maximized burn capacity while minimizing the impacts on air quality. It can also help to reduce the risk of human exposure to high levels of fire smoke.

Current air quality forecasting systems are not equipped with the tools necessary for the dynamic management of PB operations. Typically, prescribed fires are assumed to be county-wide area sources with emissions equal to the average of several past years. The day-specific emissions used in the forecasts are generated by taking the rolling average over a specified period of daily prescribed fire emissions in a particular county for the years included in the average [11]. For example, if the selected averaging period is + / 7 days and the years included are 2011-2015, then for 15 April, all fires in that county are averaged from 8 April to 22 April for 5 years between 2011 and 2015. Such averaging greatly reduces the day-to-day variability compared to the actual prescribed fire emissions. It also smooths out the fires spatially by averaging multiple years of fire emissions over each county. The result is more frequent, but less intense, fires over larger spans, which is not appropriate for an air quality forecasting system to be used in dynamic management. The National Air Quality Forecasting Capability (NAQFC)

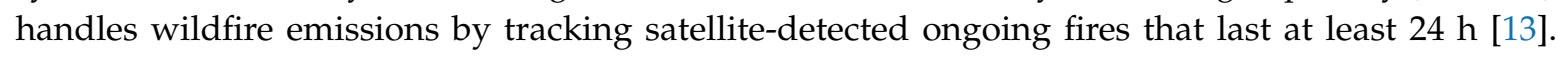
Prescribed fires are typically of shorter duration; they burn out in a few hours after their detection. Therefore, prescribed fires cannot be tracked in the same manner as wildfires for air quality forecasting purposes. Estimating prescribed fire emissions from satellites is also problematic as it has been shown that satellites seriously underestimate the burn areas in Southeastern USA [4]. What is needed is a burn activity and impact forecasting system that can provide information well in advance so that burns can be managed through the existing permitting systems.

Using a decision tree, we built a model to forecast how much PB activity is going to occur, when and where in Georgia, based on weather and historic burning patterns. Classification and 
regression trees are one of the simplest and easiest to interpret statistical learning methods that can be built to make a prediction for an observation from predictor variables. Since they split the predictor space into segments that look like the branches of a tree, they are called tree models. In the past, classification and regression trees have been used in the air quality field for various other purposes. Examples include the generation of annual mean concentrations from short episodes [14], model evaluation [15,16], the prediction of peak ozone or $\mathrm{PM}_{2.5}$ episodes [17], and air pollution epidemiology [18]. To our knowledge, this is the first time a decision tree has been used to forecast prescribed fire activity. We started using this burn activity model to forecast prescribed fire emissions and their impacts on air quality using an air quality forecasting system.

In what follows, the burn activity forecasting decision tree model and the methods used for prescribed fire emissions estimation are described in detail. The air quality forecasting system and its fire impact forecasting capability are reviewed. An evaluation of the burn activity forecasts during the test operation in 2015 and the production operation in 2016 are presented. This evaluation includes comparisons to satellite observations and ground-based accounts of fires. The skill of the forecasting system in predicting PB impacts is evaluated by comparisons to smoke-induced peaks in observed pollutant levels at network monitors in 2016.

\section{Methodology}

In this section, the method used for burn activity forecasting is described in detail. Then, the emission estimation method, the air quality forecasting system and its fire impact forecasting capability are overviewed. Finally, the metrics used for the evaluation of the forecasts are defined.

\subsection{Burn Activity Forecasting}

To conduct safe and effective burns, the fuels must be dry enough to catch fire but not so dry that they burn uncontrollably. Similarly, the winds must be strong enough to spread the fire over the land to be treated but not strong enough to carry the flames beyond the perimeter. Based on these guidelines, the weather forecast can be used to predict PB activity, at least on a burn/no-burn decision level.

In Georgia, according to the Prescribed Burning Act of 1992, a permit is required for the PB of woods, lands, marshes, or other flammable vegetation. The Georgia Forestry Commission (GFC) is the agency in charge of issuing permits and keeping permit records. The burn season for most sites in GA is from 1 October to 30 April of the next year. A burn ban goes into effect in 54 counties during the ozone season (1 May-30 September). We obtained permit record data from GFC for the years 2010-2016. Considering the burn season restriction, we focused our analysis on the first four months of each calendar year. The database contains the date and time, location and area of the burn, along with other information such as the purpose of the burn and the contact information of the burner. While some permit records have coordinates of the burn location, non-standard addresses that cannot be readily georeferenced are also common, but all records contain the county of the burn location; therefore, the spatial resolution of our analysis was set at the county level. GFC makes available daily weather forecast as well as observed weather data in an archive for fire danger ratings on its website. We downloaded the data for the 2010-2016 period at 18 fire weather stations in Georgia from this website. Information on how to download the data can be found in Appendix A.

A preliminary analysis of the data revealed that weather plays an important role in the decision of the burner [11]. In general, burns were not attempted on rainy days, days following large rain events or during prolonged dry periods. Surface wind speeds were generally between 5 and $15 \mathrm{mph}$ on the days when most burns were conducted. These findings as well as a weather forecast can be used as a first indicator of upcoming burn activity. Analysis has also shown that the amount of acreage treated by fire increases when weather conditions are more favorable for conducting safe and effective burns. This trend along with historic burning patterns employed by a list of likely burners can be used to predict the location and size of the burns. The more precise the prediction of PB activity and emissions, the more accurate the fire impact forecasting will be. 


\subsubsection{Burn Days}

The response variable is data labeled with two classes-burn day or no-burn day-coded as a binary variable. When the total burn area in a county on a particular day was greater than 30 ha, it was considered to be a burn day in that county and it was assigned a value of 1 ; otherwise it was a no-burn day and was given a value of 0 . The 30-ha limit was determined from the distribution of daily total burn areas by county and is approximately equal to the mean minus one standard deviation. A set of 21 variables from the fire danger rating data were selected as predictor variables. A detailed description of these variables can be found in Appendix A. Missing values, most commonly for wind speed, were replaced by the average of the available values in the dataset for that variable. Data for the years 2010-2014 were used to train the model. Later, the model was evaluated using the data for January-April 2015.

The Classification and Regression Tree (CART) is a classification method that constructs a decision tree model using historical training samples which can then be used to classify new, unseen data. For the details of the algorithm, please see Appendix B. The CART classifier is a binary decision tree, which is constructed by splitting the learning data into two branches, recursively. An example of a decision tree generated by CART and a graphical representation of the decision boundary are shown in Figures A1 and A2, respectively. CART selects the best predictors on its own, prioritizes them and discards the least important ones. CART is non-parametric, i.e., it does not make any assumptions about the statistical distribution of variables, unlike linear regression which has two parameters-slope and intercept. CART can handle outliers that affect other models such as linear regression.

The decision tree classifier model was implemented in python programming language using the Scikit-learn library [19]. Scikit-learn uses an optimized version of the CART algorithm. Information gain between two nodes is selected as splitting criteria for growing the tree. This is calculated using information entropy between the nodes as shown in Figure A3. The predictor variable which gives the highest information gain is placed at the root node and this procedure continues recursively to grow the tree. If we let the decision tree grow until all of the samples are classified, then it may overfit the training data. An overfitted decision tree tends to address noise instead of the underlying relationship. Hence, we needed to specify and limit the depth to which the tree could grow. This is called "pruning" the tree. The optimal depth was determined by measuring the model's performance on the evaluation dataset. Performance evaluation will be described in Section 2.4 below. The decision tree model was trained with a range of depths, and the shallowest tree with the best forecasting performance was selected. Because of pruning, some of the 21 variables included in training may have been excluded from the decision tree model.

Two types of models were trained: a statewide model and county-specific models. In the statewide model, one decision tree model was trained to forecast PB activity for the entire state. To train the model, burn permit data of the counties in which the 18 fire weather stations reside were used. A single training dataset was created by concatenating the fire weather data from the 18 stations and the corresponding burn permit data. A single decision tree was then trained with this dataset. The depth of the tree was optimized by the pruning methodology discussed above. Once the decision tree model was trained, every county in Georgia (159 counties in total) was assigned a station near to it. Forecast fire danger data from each assigned station was used to forecast PB activity for the corresponding county.

In the county-specific models, every county had its own optimal decision tree for forecasting PB activity. When assigning a fire weather station to a county, the following methodology was used: First, for every county, 18 optimal decision trees were trained using that county's burn permit data, and each of the 18 fire weather stations' data. The forecasting performances obtained from each of these 18 models were noted. Further, the distances between the county and the 18 fire weather stations were calculated. The nearest fire weather station did not always yield the best performance. We selected the station that produced the best forecasting performance among the nearby stations. The burn permit data in that county were then used along with the fire danger data observed at the assigned station to train the decision tree model. The depth of the tree was optimized by the pruning 
methodology discussed above. This procedure was followed to build PB forecasting models for all of the 159 counties in Georgia. To forecast PB activity in a county, the forecast fire danger rating data from the assigned station were fed to the model customized for that county.

\subsubsection{Burn Areas}

Georgia is one of the most active states in applying PB in the USA. Using the fire weather forecast data as input, the decision tree model forecasts whether it is going to be a burn day or not in a particular county. Once a burn day is forecast, the next step in the process of forecasting PB impacts on air quality is estimating the size and the location of these burns. First, we determined the daily average total burn area for each county. For the 2015 burning season, we used the statewide model, and we assigned the annual average daily burn area to a county for every burn day that was forecast. Since there is strong seasonality associated with the amount of $\mathrm{PB}$, while implementing the county-specific models for the 2016 burning season, we used monthly average daily burn areas. This approach led to more accurate monthly total burn areas than using the annual average daily burn areas.

To characterize the sizes of the burns, we grouped the counties in Georgia into three categories according to their burner type-single dominant, multiple large and various small burners (Appendix C) —and assigned them typical burn sizes of 120, 80, and 40 ha, respectively. By dividing the county total burn area to the typical burn size assigned to the county, we determined the number of burns and randomly distributed that many burns of typical size to the forested areas of that county.

\subsection{PB Emission Estimation}

Once the location and the size of the burns are forecast, the next step in PB impact prediction is the estimation of emissions from the burns. Emission estimation starts with estimation of the fuel load and fuel consumption. A detailed description of the procedure used for emission estimation can be found in Davis et al. [20]. We currently use the Fuel Characteristic Classification System (FCCS) fuel-bed maps to determine the fuel loads in burn locations assigned to each county. In the future, more up-to-date satellite products can be used to estimate the fuel loads in each grid cell where the burns are located. As for the determination of the fuel moistures required for the calculation of fuel consumption, we use the previous day's fuel moistures reported by the statewide Fire Weather Network. In the future, these fuel moistures can be modified according to the weather forecast for the burn day. Emissions are calculated by multiplying the forecast burn area with the fuel loads per unit area, the combustion efficiency and the emission factors (i.e., mass of $\mathrm{PM}_{2.5}$ and other pollutants emitted per unit mass of fuel burned) for Southeastern fuels published by the US Forest Service [21].

Since most prescribed fires in the Southeastern US are low intensity fires [22], we assume that the plumes do not penetrate the free troposphere. The resulting emissions are currently mixed into the planetary boundary layer (PBL) portion of a vertical column of $4 \mathrm{~km} \times 4 \mathrm{~km}$ grid cells over the burn location. This procedure was designed after conducting a sensitivity study to understand the influence of the vertical distribution of emissions [23]. Figure 10 in Garcia-Menendez et al. [23] shows that modeled $\mathrm{PM}_{2.5}$ concentrations at a receptor are not too sensitive to the vertical distribution of fire emissions below the PBL height.

\subsection{Air Quality and PB Impact Modeling}

We have expanded our air quality forecasting system, HiRes [15], to forecast the impacts of various types of emission sources for dynamic management purposes [12]. Using the sensitivities calculated by the decoupled direct method (DDM) [24] available in the Community Multiscale Air Quality (CMAQ) model (version 5.0.2), the impacts of $\mathrm{PB}$ emissions to the forecast ozone and $\mathrm{PM}_{2.5}$ concentrations are calculated. The new system, HiRes2, which consists of the Weather Research and Forecasting model (WRF) (version 3.6) and CMAQ, has been operational since 1 January 2015. DDM requires a well-defined emission source for each sensitivity that it calculates, and additional sensitivity calculations significantly increase the computational burden. We treat all PB emissions in Georgia as a single source and calculate a single DDM 
sensitivity to statewide PB. Additional DDM sensitivity calculations are required to determine the impacts of $\mathrm{PB}$ emissions from a specific fire district or county within the state.

The air quality and burn impact forecasts are reported daily via a website [25]. Figure 1 shows the $\mathrm{PM}_{2.5}$ and $\mathrm{PB}$ impact forecasts for 9 March 2016 as an example of a high burn activity day. Exceedance of the $35 \mu \mathrm{g} \mathrm{m}^{-3}$ daily average $\mathrm{PM}_{2.5}$ standard is expected for the purple colored grid cells in Figure 1a. The PB impacts shown in Figure $1 \mathrm{~b}$ are responsible for the exceedances. With this information, the amount of area permitted to be burned can be restricted to avoid the forecast exceedances. The website also contains numerical information for maximum $\mathrm{PM}_{2.5}$ concentrations and $\mathrm{PB}$ impacts in each county along with the forecast burn areas.

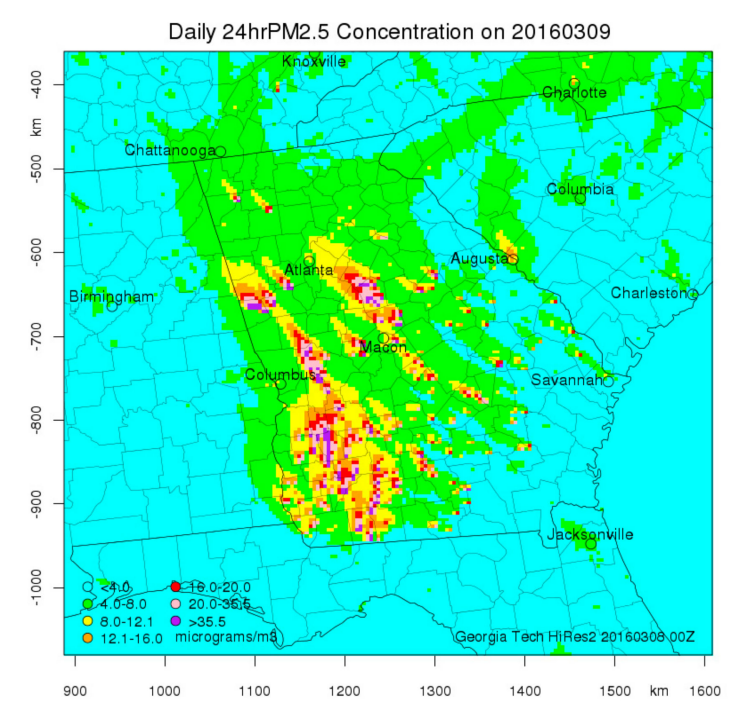

(a)

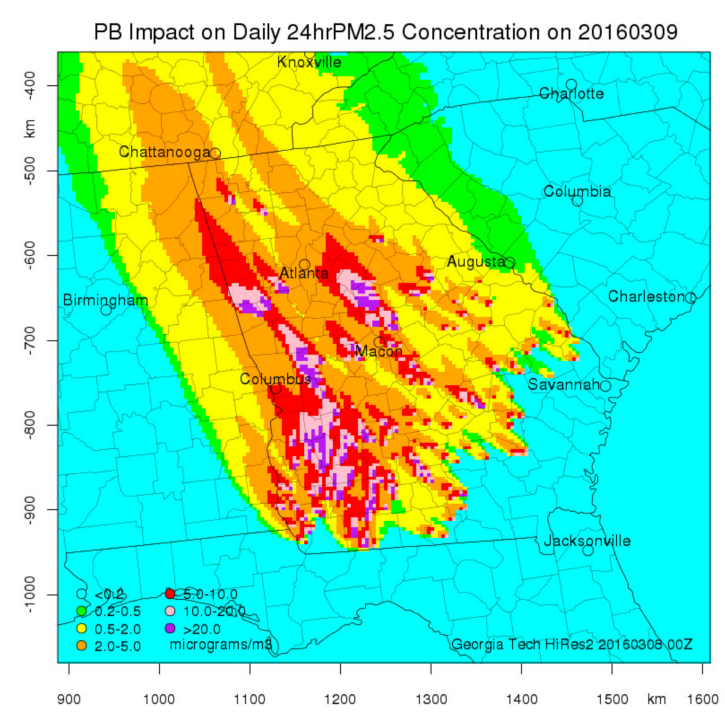

(b)

Figure 1. Illustration of HiRes2 daily forecast products: (a) 24-h average $\mathrm{PM}_{2.5}$ (particulate matter with an aerodynamic diameter smaller than $2.5 \mu \mathrm{m})$ concentrations $\left(\mu \mathrm{g} \mathrm{m}^{-3}\right)$ on 9 March 2016 and; (b) on a different scale, the portion of $\mathrm{PM}_{2.5}$ associated with prescribed burns in Georgia USA.

\subsection{Forecast Evaluation}

Forecasts are evaluated as binary occurrences. The divide between a positive occurrence and a negative occurrence is determined based on certain criteria. For example, recall that we defined a burn day as a day with total burn area of 30 ha or more in a county. In this example, a true positive is a correctly predicted burn day, a false positive is an incorrectly predicted burn day and a false negative is an incorrectly predicted no-burn day. True positives $(t p)$, false positives $(f p)$, and false negatives $(f n)$ are counted and the following metrics are used in evaluating the forecast performance. Precision, $p$, is the measure of true positives from the total predicted positives:

$$
p=\frac{t p}{t p+f p} .
$$

Recall, $r$, is the measure of true positives from the total observed positives:

$$
r=\frac{t p}{t p+f n}
$$

F1 score is the harmonic mean of precision and recall:

$$
F 1=\frac{2 \times p \times r}{p+r} .
$$


True negatives $(t n)$ or correctly predicted no-burn days are also important from an accuracy point of view. Accuracy, $a$, measures the overall correctness of the model:

$$
a=\frac{t p+t n}{t p+f p+t n+f n} .
$$

The number of no-burn days exceeds the number of burn days by a large margin, and since we are more interested in correctly predicting the burn days, accuracy can be a deceiving performance measure. A burn day forecast model can yield high accuracy even if it misses the majority of the burn days. On the other hand, the $F 1$ score places more importance on the burn days, whether they are predicted correctly or missed, or whether the model predicts false burn days; therefore, it is a better performance measure than the accuracy. However, the $F 1$ score treats $f p$ and $f n$ equally while, in reality, those occurrences may have different consequences. A metric that weighs $f p$ and $f n$ according to the economic value of their consequences might be better suited for forecast evaluation and should be considered in the future.

\section{Results}

In this section, first, the burn activity forecasts during the test operation in 2015 and the production operation in 2016 are first evaluated. This evaluation includes comparisons to satellite observations and ground-based accounts of fires. Then, the skill of the forecasting system in predicting PB impacts is evaluated by comparisons to smoke-induced peaks in observed pollutant levels at network monitors in 2016.

\subsection{Evaluation of Burn Day Forecasts}

The statewide model was used for burn impact forecasting in 2015, while county-specific models were used in 2016. The 2015 burn day forecasts were repeated with the county-specific models, and the F1 scores calculated for each county were compared to those obtained with the statewide model. Using county-specific decision trees, burn day forecasting performance improved significantly for the 2015 burning season, compared to the use of a single, statewide model (Figure 2).

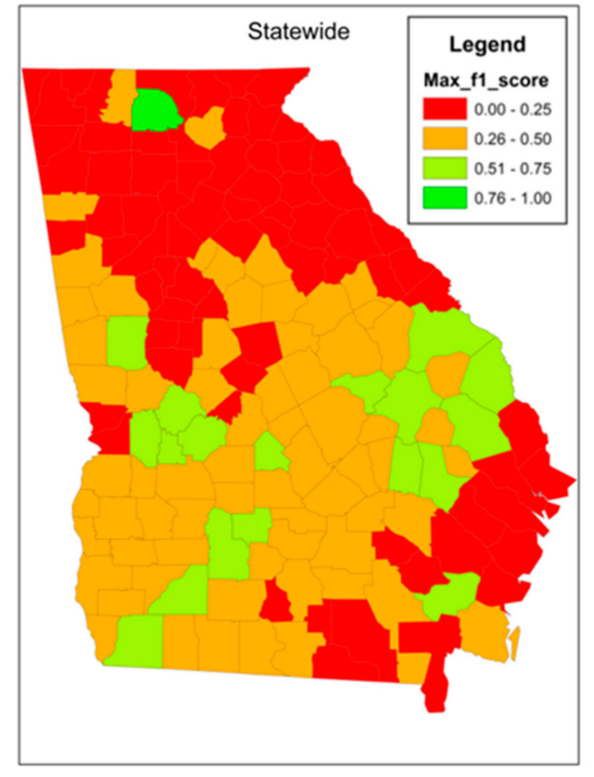

(a)

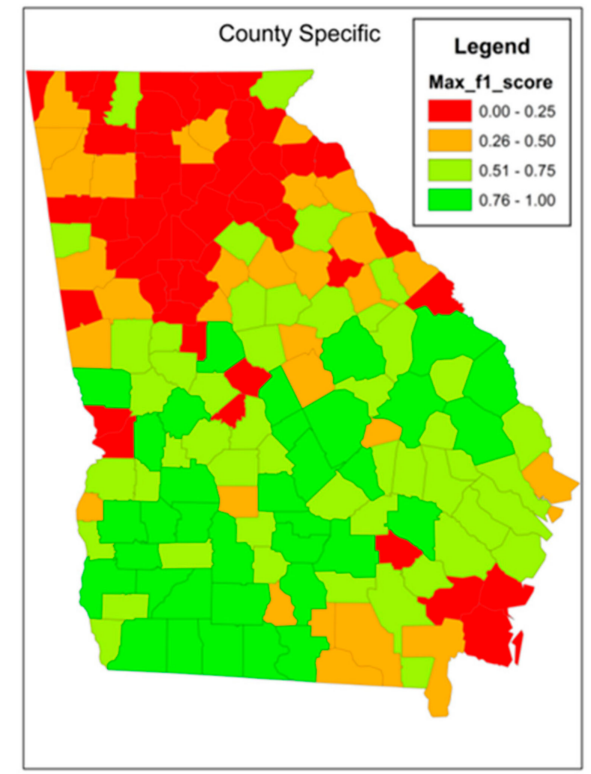

(b)

Figure 2. January-April 2015 burn day forecast $F 1$ scores by county for the (a) statewide and (b) county-specific decision tree models. 
We used the Hazard Mapping System (HMS) Fire and Smoke Analyses by NOAA [26] for qualitative evaluation of our forecasts. Every day, we compared our burn forecasts to the daily analyses by NOAA and gave them a rating based on the agreement in regard to the location and density of the fires. Figure 3 shows an example where the rating was "excellent". This subjective rating was given based on the agreement both in location and density of the fires between the forecast and the analysis, everywhere except in Northeastern Georgia where the cloud cover may have obstructed the satellite's view. It should also be kept in mind that other factors, such as the forest canopy, can also interfere with the satellite retrieval. We used the highest impacts of the burns on $\mathrm{PM}_{2.5}$ concentrations (shown in purple in Figure $3 b$ ) as a proxy for the locations of the burns. Also, since the burn forecast is for Georgia only, the fires observed in other states were ignored for the purposes of this evaluation.

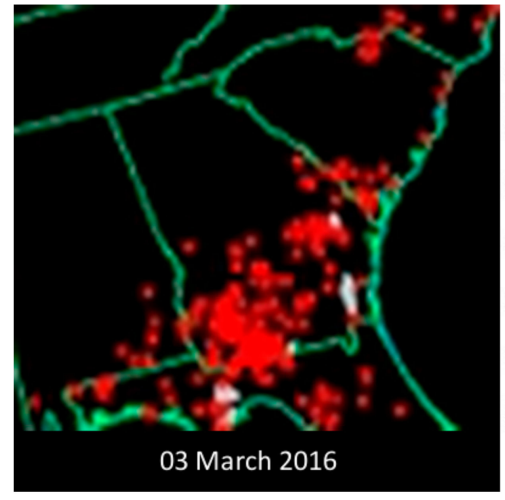

(a)

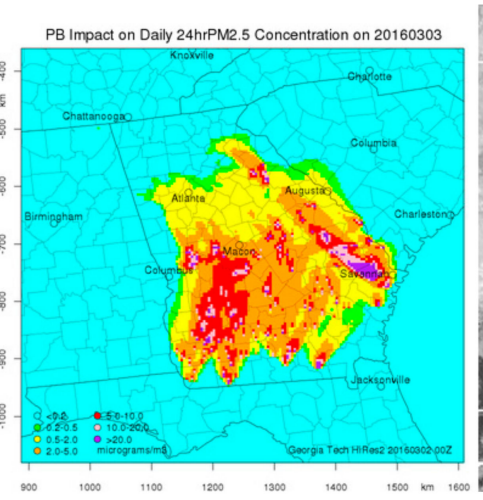

(b)

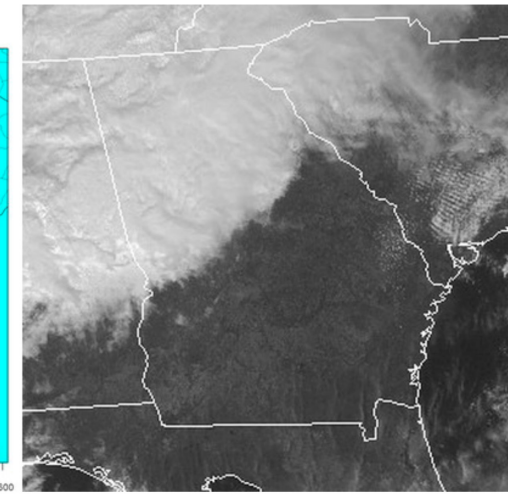

(c)

Figure 3. (a) NOAA's Hazard Mapping System Fire and Smoke Analysis; (b) forecast of burn impacts on $\mathrm{PM}_{2.5}$ levels; and (c) cloud cover for 3 March 2016. The largest impacts on $\mathrm{PM}_{2.5}$ (shown in purple) can be used as a proxy for burn locations.

This qualitative evaluation is conducted as a first indication of the suitability of the burn forecast. Clearly, the ability to correctly predict the locations of the burns influences the accuracy of the fire impact forecasts at specific air quality receptors. A "good" or better rating warrants more detailed analysis, including qualitative evaluation. The number of good or better agreement days increased in 2016 with the county-specific models compared to 2015 when the statewide model was used for PB impact forecasting, especially in March when the burn activity peaked.

\subsection{Evaluation of Burn Area Forecasts}

By regressing forecast versus permitted daily total burn area statewide, we estimated the temporal accuracy of the models in forecasting the PB area. Figure 4 shows the regression lines for both the statewide and county-specific models. The coefficients of regression (slope and intercept) with margins of error (using $95 \%$ confidence interval), the coefficient of determination $\left(R^{2}\right)$ and the standard error of estimate $(\sigma(y))$ are also shown. Each data point in these scatter plots represents a day from the January-April 2015 period. For both models, there are more points below the 1:1 line indicating an overall underestimation of daily total burn areas. In general, small burn area totals were overestimated while large totals were underestimated. This was more pronounced with the county-specific models which underestimated all burn totals above 7000 ha. The standard error of estimate given by the county-specific models ( $2170 \mathrm{ha}$ ) was smaller than that of the statewide model (5070 ha); also, the $\mathrm{R}^{2}$ of regression was larger in the case of county-specific models (0.34) than that of the statewide model (0.11). 


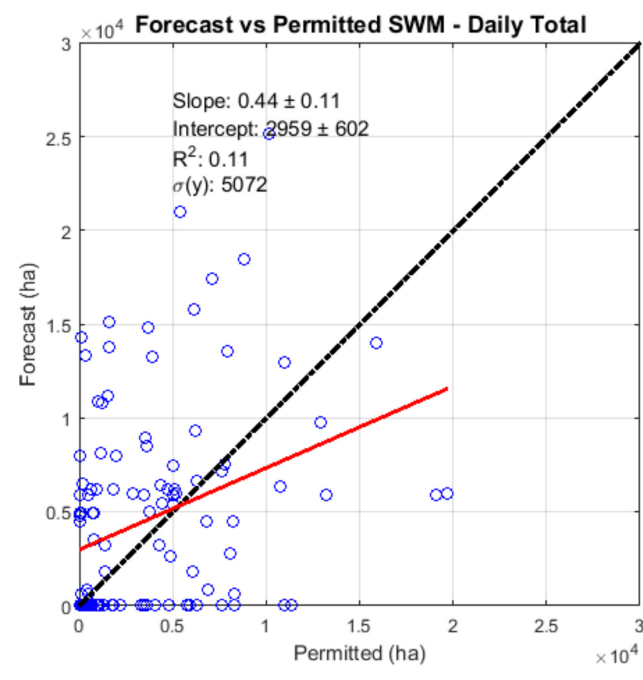

(a)

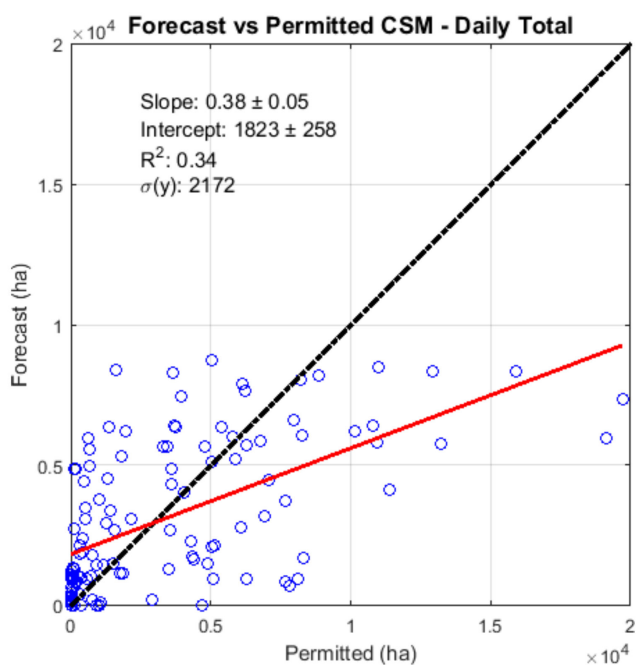

(b)

Figure 4. Forecast versus permitted daily total burn areas (ha) in Georgia for the January-April 2015 period: (a) statewide model; and (b) county-specific models.

The regression of forecast versus permitted county total $\mathrm{PB}$ area over the season gave us an idea about the spatial accuracy of the models in forecasting PB area. Figure 5 depicts the regression lines for both the statewide and county-specific models. Each data point in these scatter plots represents a county. Once again, the burn areas were generally underestimated, the standard error of estimate given by the county-specific models ( $2150 \mathrm{ha}$ ) was smaller than that by the statewide model ( $2820 \mathrm{ha}$ ) and the $\mathrm{R}^{2}$ of regression was larger in the case of county-specific models (0.47) than that in the statewide model (0.29).

The slope and $R^{2}$ values for the regressions of the county totals in Figure 5 were greater than those for the regressions of the daily totals in Figure 4. Further, both the intercepts of the lines and the standard errors of the estimates were smaller for the county totals than those for the daily totals. Therefore, the overall spatial accuracy in forecasting the location of the burns at the county level resolution was higher than the temporal accuracy in forecasting the day of the burns.

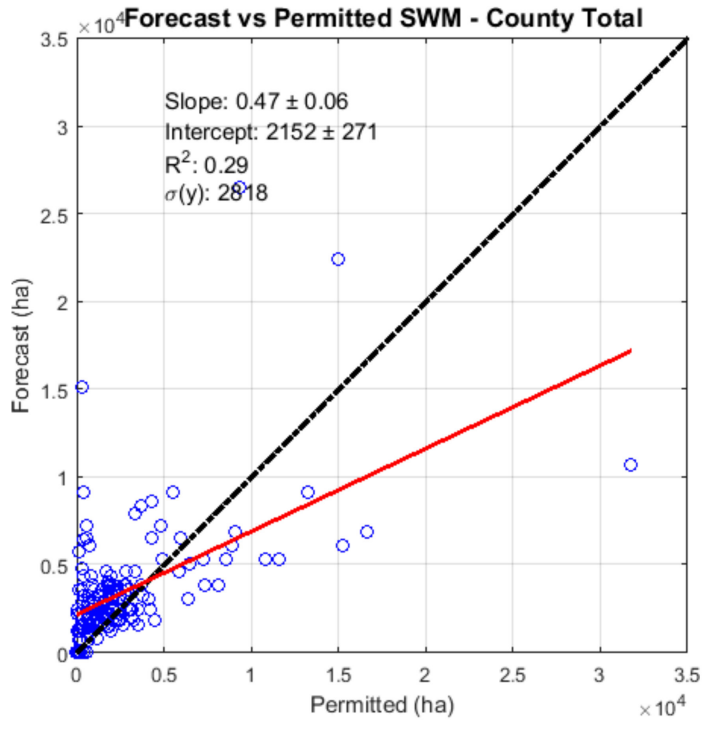

(a)

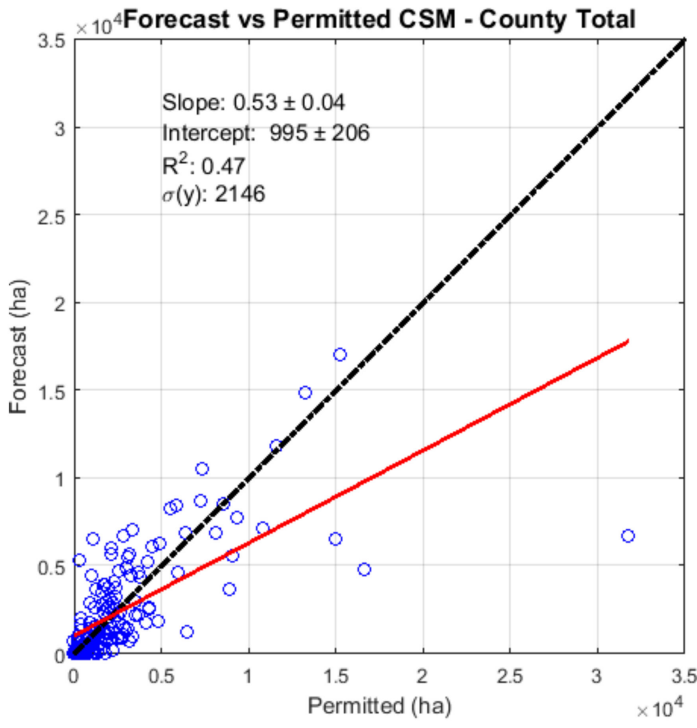

(b)

Figure 5. Forecast versus permitted county total burn areas (in ha) in Georgia for the January-April 2015 period: (a) statewide model; and (b) county-specific models. 
We expected similar performance for the burn area forecast in 2016. However, when we compared our forecast burn areas to the permitted burn areas, we found that the underestimation in forecast burn areas was greater both in terms of daily statewide totals and county totals for the 2016 burn season (Figure 6). From January to April 2016, a total of 480,000 ha was permitted to be treated by PB while only 200,000 ha was forecast. The correlation between forecast and permitted burn areas has also degraded compared to 2015. In contrast to 2015, the spatial accuracy in forecasting the burns in each county was worse than the temporal accuracy in forecasting the day of the burns. These changes in the performance of the burn area forecast were most likely because of the El Niño-Southern Oscillation (ENSO) and the La Niña conditions of 2015-2016 that created very different precipitation patterns in Southeastern USA during the 2016 burning season compared to the 2010-2014 period. The temperatures during the month of March, at the peak of PB activity, were much above average and precipitation was below average (www.ncdc.noaa.gov/temp-and-precip).

Burn areas in permit records during the first four months of 2016 increased by $20 \%$, from 400,000 ha in 2015 to 480,000 ha in 2016. This may have played a significant role in the underestimation of the daily total burn areas that were being forecast based on 2010-2014 averages, supporting the role of atypical weather during the first four months of 2016. Despite the overall underestimation of burn areas, there were still a large number of days and counties where burn areas were overestimated. In Figure 6, these are the points remaining above the 1:1 line, and for almost all of them, the permitted burn areas are below 4000 ha.

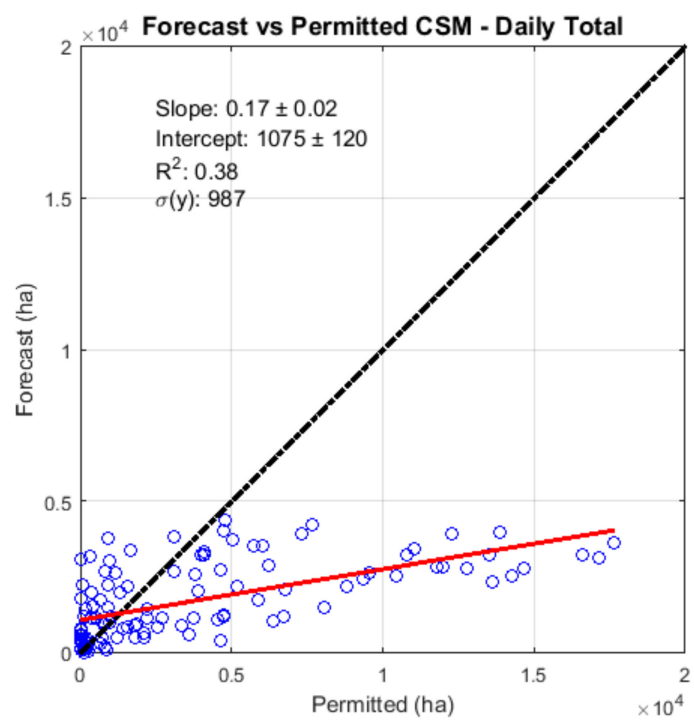

(a)

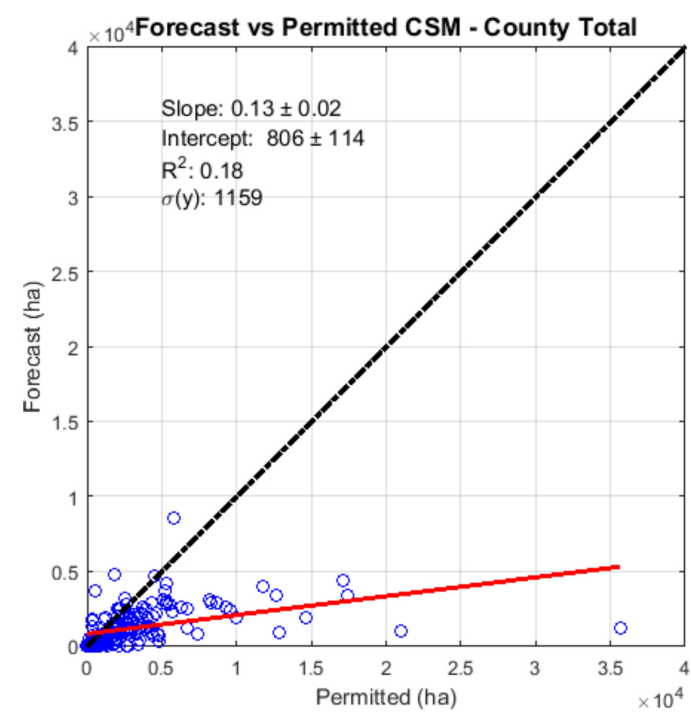

(b)

Figure 6. Forecast from county-specific models versus permitted (a) daily total burn areas in Georgia; and (b) county total burn areas for the January-April 2016 period.

\subsection{Evaluation of Burn Impact Forecasts}

The overall statistics of the 2016 burn impact forecasts are shown in Figure 7. If the maximum afternoon $\mathrm{PM}_{2.5}$ concentration on a particular day is in the 95th percentile of all observed afternoon maximum concentrations during the burn season, then that monitor is most likely impacted by PB. To be sure, burn permits in the county in which the monitor resides as well as the counties surrounding the monitor were reviewed to see if there were any permitted burns that may have affected the observations on that day. The 95th percentile of all observed afternoon $\mathrm{PM}_{2.5}$ concentrations was $32 \mu \mathrm{g} \mathrm{m}^{-3}$. On the other hand, the 95th percentile of all forecast maximum afternoon $\mathrm{PM}_{2.5}$ concentrations was $43 \mu \mathrm{g} \mathrm{m}^{-3}$. The common threshold for forecast evaluation was set at $32 \mu \mathrm{g} \mathrm{m}^{-3}$ as shown in Figure 7. The precision, recall and $F 1$ score for correctly predicting the PB impacts over $32 \mu \mathrm{g} \mathrm{m}^{-3}$ were equal to $19 \%, 36 \%$, and $25 \%$, respectively. 


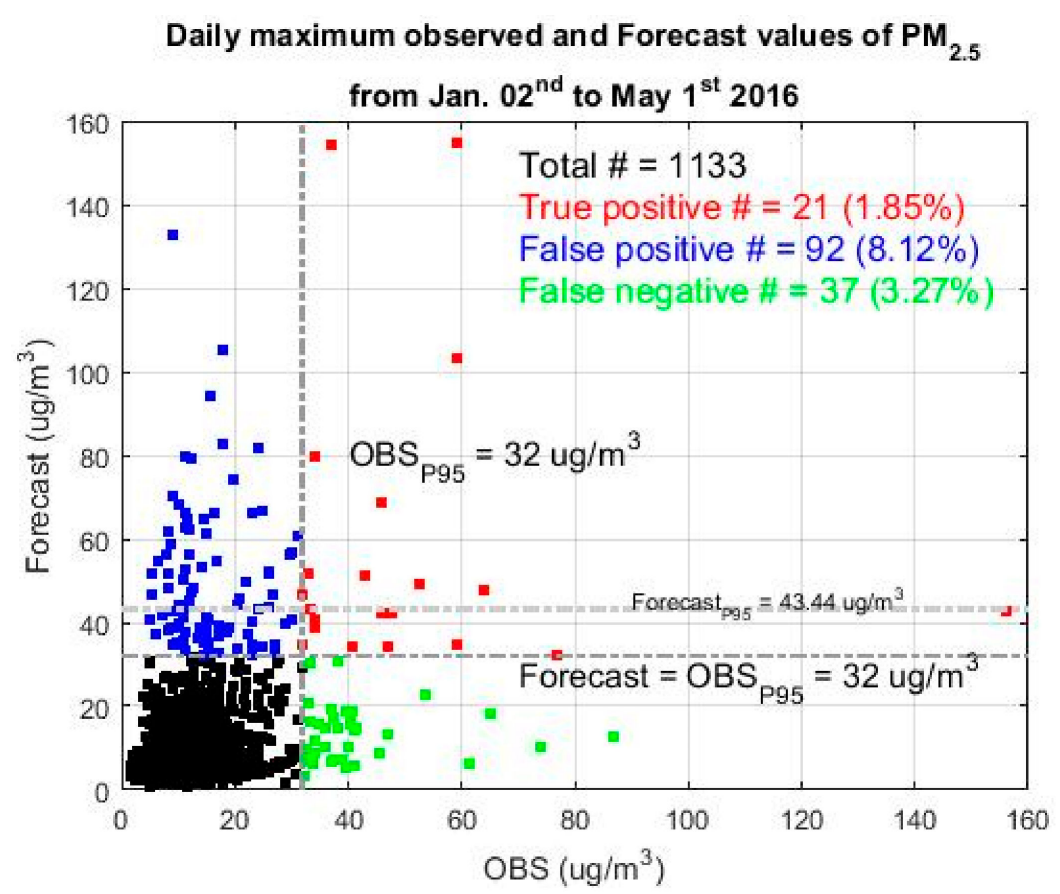

Figure 7. The 2016 burn impact forecast statistics. The thresholds for burn impacts are drawn at $32 \mu \mathrm{g} \mathrm{m}^{-3}$, which is the 95th percentile of all observed maximum afternoon $\mathrm{PM}_{2.5}$ concentrations throughout Georgia between 2 January and 1 May 2016.

The number of false positives is approximately three times as large as the number of false negatives in Figure 7, which indicates a general overestimation of the burn impacts. This may be, in part, due to the overestimation of the burn areas for low burn activity and underestimation for high burn activity days. To investigate other possible reasons, we focused on the true positives in Figure 7 and analyzed the relationship between the bias in burn impacts and the bias in burn areas. For the true positives that were associated with the $\mathrm{PM}_{2.5}$ monitors in Albany (Daugherty County) and Augusta (Richmond County), Georgia, we calculated the burn areas in the county where the monitor resides and in the immediate upwind county (or counties depending on wind direction). The difference between the forecast and permitted burn areas were normalized by the permitted burn area and plotted on the $x$-axis in Figure 8. Note that the burn areas were underestimated with the exception of one day, 24 January 2016, in Daugherty County and its upwind county. The difference between the forecast and observed afternoon maximum $\mathrm{PM}_{2.5}$ concentrations were normalized by the observed concentration and are plotted on the $y$-axis in Figure 8. The strong correlation between the two biases $\left(R^{2}=0.77\right)$ suggests that the overestimation of the burn impact may be related to an overestimation of the emissions, because the emissions are proportional to burn area. The slope of the linear regression line suggests that this emission overestimation may be around $47 \%( \pm 23 \%)$. The reason for this overestimation may be either an overestimation of the fuel consumption or high biased emission factors. The large intercept $(0.96 \pm 0.16)$ indicates that there must have been another factor that was not emission related. One potential reason is plume dispersion. The fraction of the actual smoke plumes penetrating into the free troposphere may have been larger than the fraction in our forecasts, which we assumed to be zero, leading to an overestimation of the ground-level $\mathrm{PM}_{2.5}$ concentrations at the observation sites. 


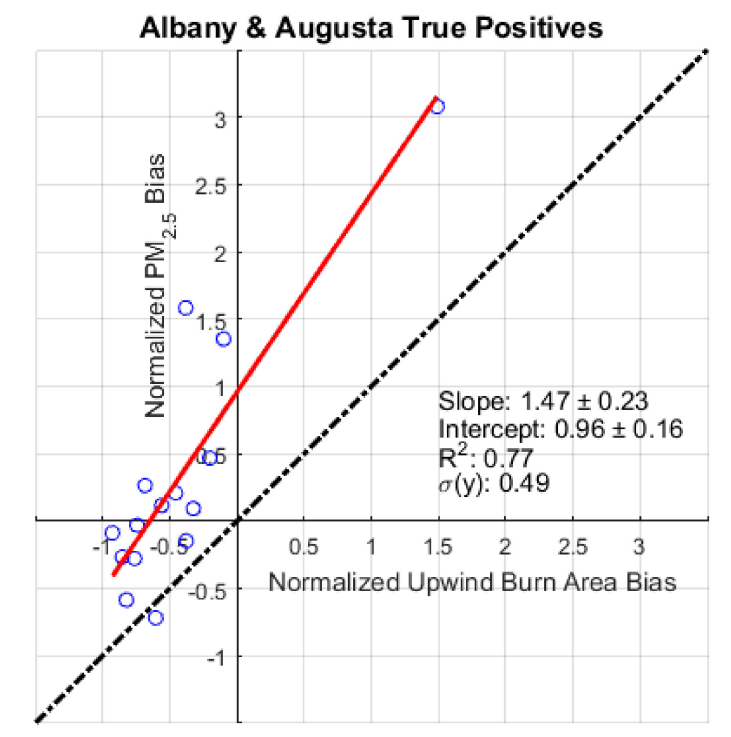

Figure 8. Normalized bias in $\mathrm{PM}_{2.5}$ versus normalized bias in burn areas in upwind counties. The burn areas were generally underestimated. Independent from the bias in burn areas, the $\mathrm{PM}_{2.5}$ impacts were mostly overestimated.

\section{Discussion}

We have developed, to the best of our knowledge, the first dynamic PB impact forecasting system. While previous air quality forecasting systems used prior year averages of $\mathrm{PB}$ emissions, this system predicts the PB activity and calculates corresponding PB emissions based on the weather forecast. It predicted active burn days at a county scale with an $F 1$ score larger than 0.50 over most of the Lower Piedmont and Coastal Plain regions of Georgia where more lands are treated with prescribed fire than the rest of the state. The PB forecast overestimated the burn areas on less active burn days while underestimating them on more active days. This may be due to using monthly average burn areas in the forecast whereas actual burn areas vary more frequently due to some days being more conducive to burns than others, as well as the random behavior of the burners. The number of correctly predicted significant smoke impacts at downwind receptors $\left(\mathrm{PM}_{2.5}\right.$ concentration larger than $32 \mu \mathrm{g} \mathrm{m}^{-3}$ ) was about six times smaller than the total number of misses and false alarms. However, there was a very strong correlation between the bias in smoke impacts and the bias in burn areas. Therefore, if the bias in forecast burn areas can be reduced, the skill in predicting smoke at downwind receptors will be greatly improved.

The current skill of the forecasting system and its potential for improvement opens new avenues for dynamic air quality and cohesive PB management. For example, the forecasting system could be used as a decision support tool, as follows. In Georgia, where a permit is required by law for PB, land managers call the GFC district offices, typically early in the morning, to obtain a permit for a burn later that day. The burn activity and burn impact forecasts provided by our forecasting system could be used by GFC to manage prescribed burns to avoid any potential exceedances through their permitting system. For example, on the morning of 18 January 2016, GFC offices could see on our website that the daily average $\mathrm{PM}_{2.5}$ concentrations in Thomson County would be as high as $75 \mu \mathrm{g} \mathrm{m}^{-3}$, with $70 \mu \mathrm{g} \mathrm{m}^{-3}$ coming from burns throughout Georgia, including 560 ha in Thomas County. Assuming the PB impact is solely from burns in Thomas County, our forecast suggests that each hectare burned will contribute $0.125 \mu \mathrm{g} \mathrm{m}^{-3}$ to the $\mathrm{PM}_{2.5}$ concentration. Therefore, to avoid exceeding the national ambient air quality standard (NAAQS) of $35 \mu \mathrm{g} \mathrm{m}^{-3}$ for daily average $\mathrm{PM}_{2.5}$, permits in Thomas County should be limited to 240 ha that day. In fact, considering potential contributions from upwind counties, the limit should be set below 240 ha. Clearly, it would be more useful to forecast exactly how many hectares can be burned in each county without violating any air quality standards. 
Our current impact forecast considers all burns in the state without distinction of local versus distant burns. Calculating the impacts of burns separately for every county by applying DDM to emissions from 159 counties in Georgia is computationally very demanding. Future research should focus on finding efficient ways of partitioning the total impact calculated by DDM into impacts of the individual counties or, better yet, individual burns upwind. If the PB impact can be broken down by specific burns, it will be seen that some burns contribute little to air quality and exposure while others contribute more. With information on the marginal contribution of each burn to the air quality downwind, the following dynamic management protocol can be employed. The burns that have minimal impact will, therefore, be permissible, while the ones that contribute a lot may have to be denied. For example, suppose burn A contributes almost nothing to the regional peak $\mathrm{PM}_{2.5}$ concentration. Burn B contributes a little bit more, but still not very much. Burn C contributes still more, and so on, say up through to burn $\mathrm{Z}$. If all burns, $\mathrm{A}-\mathrm{Z}$, were permitted, then the region might exceed the NAAQS. However, there might be a point where $\mathrm{PM}_{2.5}$ concentrations would stop short of the NAAQS, say when only burns A-N were permitted. This approach might maximize the amount of land that could be burned without going over the NAAQS. Burning any more (i.e., burns M-Z) would put the region over the NAAQS, so those burns have to be left to another day. Currently, there is a burn ban that goes into effect on 1 May in 54 counties due to the ozone season. However, there is interest in burning in May and June, and our forecasting system could identify windows of opportunity during those months. Burners that were denied earlier could be encouraged to burn during this period.

Because our burn activity forecast is the first of its kind and integrates several ad hoc elements, the burn impact forecasting system has a lot of room for improvement. One area where significant improvements can be made is the assignment of daily burn areas. Using monthly averages instead of an annual average when assigning daily burn areas to each county improved the performance of the burn forecast because of the large variation in burn activity throughout the year. However, the skewness of the burn area distribution suggests that even a monthly average may not be appropriate for capturing the variation. Recall that with monthly averages, we still underestimated high burn activity while overestimating lower activity, leading to low slopes of linear regression lines compared to 1:1 lines. A better approach may be to regress the county total daily burn areas with the same predictors that we currently use for burn/no-burn day classification. The binary decision is not able to capture varying degrees of favorable burn conditions. The burn areas under excellent burn conditions might be much larger than those under marginal conditions. A regression model is better suited than a classification model for covering the spectrum of favorable conditions and associated burn activity. When a sufficient amount of training data becomes available, a regression model should be tested. Also, other approaches such as the random forest model [27] could be tested in the future. Another area of possible improvement is the designation of burn locations within the county. By keeping track of prior permits issued and comparing them to historic burning patterns of individual burners (e.g., burn sizes, frequency, and time of the year), the demand for burning could be forecast more accurately. This may reduce, to a great extent, the need for random assignment of forecast burns to managed lands. Also, by tracking who is most likely to burn and where, accurate burn sizes could be forecast instead of the typical burn sizes that are currently fixed at 120, 80 or 40 ha according to the dominant burner type in each county.

Aside from the overestimation of burn areas for low burn activity days, uncertainties in emissions and plume heights may be among the reasons for overestimation of the burn impacts, i.e., the false positives in our forecasts. In addition, it is well known that air quality models like CMAQ typically dilute the plumes, leading to underestimation of the local impacts. Therefore, the rates of overestimation in emissions and/or underestimation of the plume heights may be more severe than our analysis suggests. Our current approach for injecting PB plumes in the vertical layers of CMAQ is based on the assumption that most prescribed burns in Southeastern USA are low intensity fires whose plumes do not penetrate the free troposphere. A better approach would be to estimate the plume height from the heat of combustion and to split the emissions between the boundary layer and the free troposphere. Beginning in 2017, we started using the plume height algorithm of Liu [28], which is based upon regressions of measured plume heights with weather-related parameters. 
Following the development and evaluation of the fire impact forecasting system, we have continued to forecast burn activity and burn impacts on a daily basis since the beginning of 2017 . These forecasts are posted regularly to our website for the benefit of regulatory agencies. We developed a protocol for incorporating the air quality and impact forecasts into the current PB permitting process in Georgia. The protocol involves denying applications or restricting the sizes of the permits on poor air quality days and encouraging burns on days when there are no imminent air quality concerns. We are focusing our research efforts on expanding our forecasts to predict the burn impacts by county and eventually, by individual burns. We are also extending our forecasts to other states in Southeastern USA. Not all states have permit records that are as comprehensive as those of Georgia. For those states, we are developing fire activity forecasts based on satellite fire detections. Although current satellites severely underestimate the burn areas of small, prescribed fires [4], we are hopeful that reliable burn impact forecasting will be possible with the increased spatiotemporal resolution of next generation satellites.

\section{Conclusions}

An analysis of the GFC burn permit database for the years 2010-2014 revealed that the season and weather play important roles in the burn/no-burn decisions made by land managers. Acreage treated by fire increases in February and March and when weather conditions are more favorable for conducting safe and effective burns. This triggered the idea of forecasting burn activity based on the time of the year and the weather forecast. A PB activity forecasting model was developed using the CART method with the daily burn areas by county from GFC's burn permit database and meteorological parameters from the closest fire weather monitors. The number of predictor variables was limited to circumvent over-modeling. The model was trained with statewide data for the years 2010-2014 and evaluated with 2015 data. Four metrics were used for evaluation: (1) the accuracy or the overall correctness of the model; (2) the precision or the accuracy in predicting burn days; (3) the recall or the number of correctly predicted burn days over the number of burn days; and (4) the F1 score, which is the harmonic mean of precision and recall. Later, considering the geographic variation in the demand for burning, this statewide model was replaced with county-specific models (a different model for each of the 159 counties in Georgia). The $F 1$ score of the burn forecasts for 2015 improved significantly with the county-specific models, showing their clear advantage over a single model for the entire state. In addition, because of the strong seasonality associated with the amount of PB, we started to employ different daily average burn areas for each month, instead of one average for the entire burn season.

If the burn-forecast model predicts a burn day, the daily average burn area for the county is split into burns of typical size, which are distributed randomly to forested areas. Then, the amount of fuel that these burns would consume is estimated using FCCS fuel load maps and fuel moisture data from the fire weather network. Fire emissions are then calculated using emission factors that are characteristic of Southeastern fuels and inpu't to the HiRes2 air quality forecasting system. HiRes2 provides forecasts of not only air quality $\left(\mathrm{O}_{3}\right.$ and $\left.\mathrm{PM}_{2.5}\right)$ but also impacts of $\mathrm{PB}$ on air quality, using the DDM sensitivity analysis method.

The forecasting skills of the PB impact prediction system were evaluated for the 2015 and 2016 burn seasons (January-April). The burn forecasts were evaluated qualitatively every day against the NOAA HMS Fire and Smoke Analyses for agreement in regard to the location and density of the fires, and quantitatively, at the end of the burn season, against burn areas permitted by GFC. In 2015, the correlation between the predicted and permitted daily statewide total burn areas was stronger with the county-specific models than with the statewide model. However, even with the better performing county-specific models, both the daily statewide total and the countywide seasonal total burn areas were generally underestimated, with some overestimations for low burn activity days or counties and large underestimations for high activity days or counties. In 2016, the underestimation was more severe than in 2015, probably due to the ENSO conditions at the beginning of the year. 
Burn impact forecasts were evaluated using observations of possible PB impacts by the statewide air quality monitoring network. In 2016, the precision, recall and $F 1$ score for correctly predicting the PB impacts over $32 \mu \mathrm{g} \mathrm{m}^{-3}$ (the 95th percentile of all observed afternoon $\mathrm{PM}_{2.5}$ concentrations at Georgia's $\mathrm{PM}_{2.5}$ monitors in 2016) were equal to $19 \%, 36 \%$, and $25 \%$, respectively. An analysis of the correlation between forecast biases showed that the bias in burn impact forecast could be reduced if the burn area forecast was improved. The unexplained portion of the bias is probably due to the uncertainty in fire emissions and/or the plume rise treatment in the modeling system, which, prior to 2017, assumed no penetration into the free troposphere.

Author Contributions: M.T.O. and M.E.C. conceived the idea of prescribed fire impact forecasting for dynamic air quality management. M.T.O. designed the forecasting system, directed the research and wrote the paper. A.G.R. provided guidance and contributed to the analysis of the data. R.D.S. and A.A.P. contributed to the development of the decision tree model for burn activity forecasting. Y.H. integrated the modeling system and conducted the forecasting operation. A.A.P. and R.H. contributed to the evaluation of the burn activity and burn impact forecasts and to the writing of the paper.

Funding: This research was funded by the National Aeronautics and Space Administration (NASA) Applied Sciences Program grant numbers NNX11AI55G and NNX16AQ29G, U.S. Environmental Protection Agency Science to Achieve Results Program grant number RD8352170, and the Joint Fire Science Program of U.S. Department of the Interior and U.S. Forest Service grant number 16-1-08-1. The costs to publish in open access are covered by NASA grant number NNX16AQ29G.

Acknowledgments: The contents of the publication are solely the responsibility of the grantee and do not necessarily represent the official views of the supporting agencies. Further, The USA Government does not endorse the purchase of any commercial products or services mentioned in the publication. We thank Daniel Chan and Frank Sorrels of Georgia Forestry Commission for providing the Georgia prescribed burn permit data.

Conflicts of Interest: The authors declare no conflict of interest. The funding sponsors had no role in the design of the study; in the collection, analyses, or interpretation of data; in the writing of the manuscript, and in the decision to publish the results.

\section{Appendix A}

We obtained the fire danger rating data for the 2010-2016 period, available for 18 fire weather stations in Georgia, from http:/ / weather.gfc.state.ga.us/SearchPrompt.aspx. By selecting Fire Danger Rating under Type of Forecast, one can obtain the observed fire danger rating data at all stations for a desired month. Twenty-one variables from the fire danger rating data were used as predictor variables (Table A1). The values are observed values at the stations at 1 p.m. EST.

Table A1. Dataset of variables in fire danger rating.

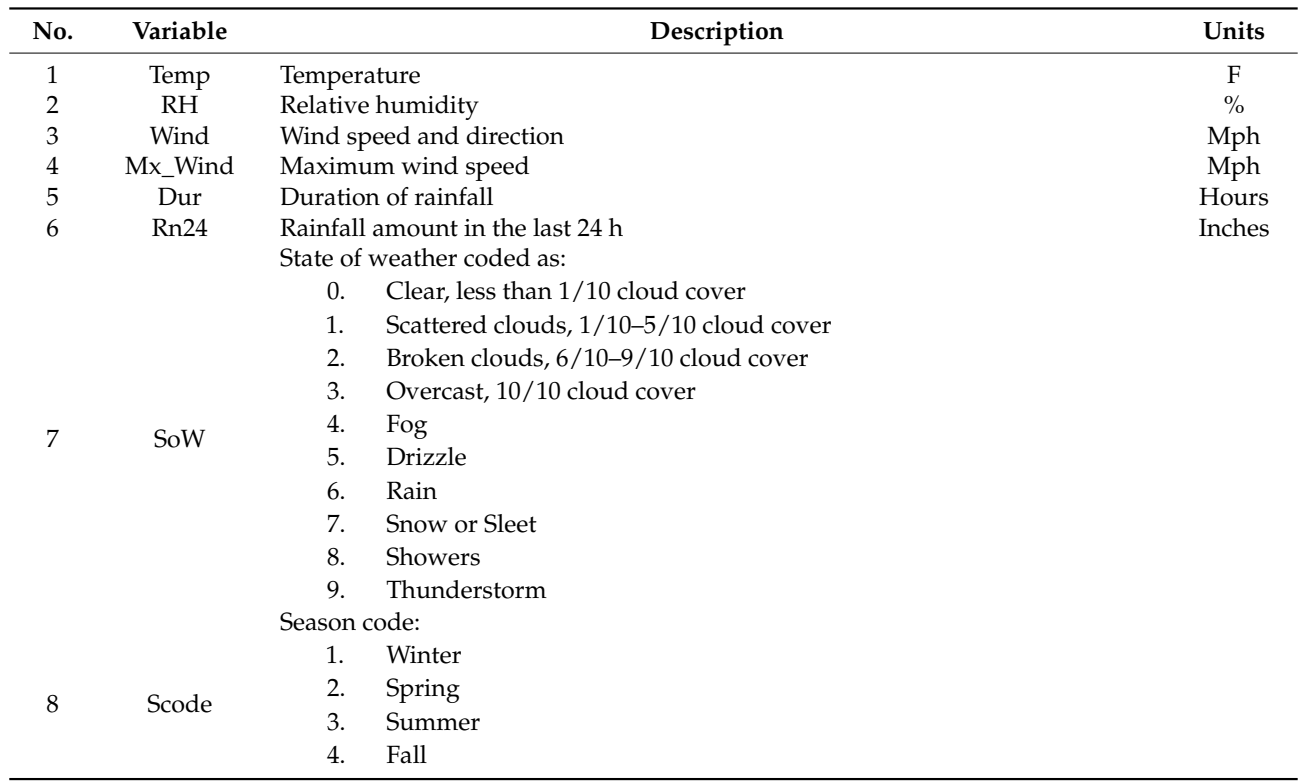


Table A1. Cont.

\begin{tabular}{|c|c|c|c|}
\hline No. & Variable & Description & Units \\
\hline 9 & KBDI & $\begin{array}{l}\text { Keetch-Byram Drought Index (KBDI) measures moisture in deep duffs or upper } \\
\text { soil layers. The relative dryness of soil is important in fire suppression. KBDI } \\
\text { varies from } 0 \text { (wet) to } 800 \text { (dry). }\end{array}$ & \\
\hline 10 & Tmax & Maximum temperature in the last $24 \mathrm{~h}$ & $\mathrm{~F}$ \\
\hline 11 & Tmin & Minimum temperature in the last $24 \mathrm{~h}$ & $\mathrm{~F}$ \\
\hline 12 & RHMax & Maximum relative humidity in the last $24 \mathrm{~h}$ & $\%$ \\
\hline 13 & RHMin & Minimum relative humidity in the last $24 \mathrm{~h}$ & $\%$ \\
\hline 14 & HrbGF & $\begin{array}{l}\text { Herbaceous greenup factor (HGF): the actual greening and curing of live } \\
\text { herbaceous vegetation. HGF varies from } 0 \text { (completely cured) to } 20 \text { (completely } \\
\text { green). }\end{array}$ & \\
\hline 15 & WdyGF & $\begin{array}{l}\text { Woody greenup factor (WGF): this expresses the actual greening and curing of } \\
\text { live woody vegetation. WGF varies from } 0 \text { (completely cured) to } 20 \text { (completely } \\
\text { green). }\end{array}$ & \\
\hline 16 & Herba-ceous & Fuel moisture in live herbaceous vegetation. & $\%$ \\
\hline 17 & Woody & Fuel moisture in live woody vegetation. & $\%$ \\
\hline 18 & $\mathrm{SC}$ & Spread component: this is the forward rate of spread at the head of the fire. & $\mathrm{ft}_{\min ^{-1}}$ \\
\hline 19 & $\mathrm{EC}$ & $\begin{array}{l}\text { Energy release component: this is the potential available energy per unit area at } \\
\text { the head of the fire. }\end{array}$ & $\begin{array}{l}\mathrm{BTU} \\
\mathrm{ft}^{-2}\end{array}$ \\
\hline 20 & BI & $\begin{array}{l}\text { Burning index (BI): dividing BI by } 10 \text { gives a reasonable estimate of the flame } \\
\text { length in feet at the head of a fire. BI is fuel model dependent factor. } \\
\text { Class of day, describing the potential for wildland fires, coded as: }\end{array}$ & \\
\hline 21 & Class Day & $\begin{array}{ll}\text { 1. } & \text { Low } \\
\text { 2. } & \text { Moderate } \\
\text { 3. } & \text { Very high } \\
\text { 4. } & \text { Extreme }\end{array}$ & \\
\hline
\end{tabular}

\section{Appendix B}

A detailed description of the CART algorithm can be found in Breiman et al. [29]. Here, we will highlight its principal elements.

The root node in Figure A1 includes all of the training samples to start with. The training samples are then partitioned by decision boundaries using predictor variables-variable 1 and variable 2 here (Figure A2). Each node of the tree, except for the terminal node, represents a conditional question to the predictor data. If the value of a predictor is greater than a certain value, then the left branch of the tree is chosen; otherwise the right branch is chosen. If we keep doing this at every node, we reach a terminal node where we obtain the probabilities for each class. $P_{i, j, k}$ is the probability of class $i$ at level $j$ and node $k$. If the probability for a class is greater than a defined threshold value (generally 0.5) then we make the forecast for that class: 'burn day' or 'no-burn day'.

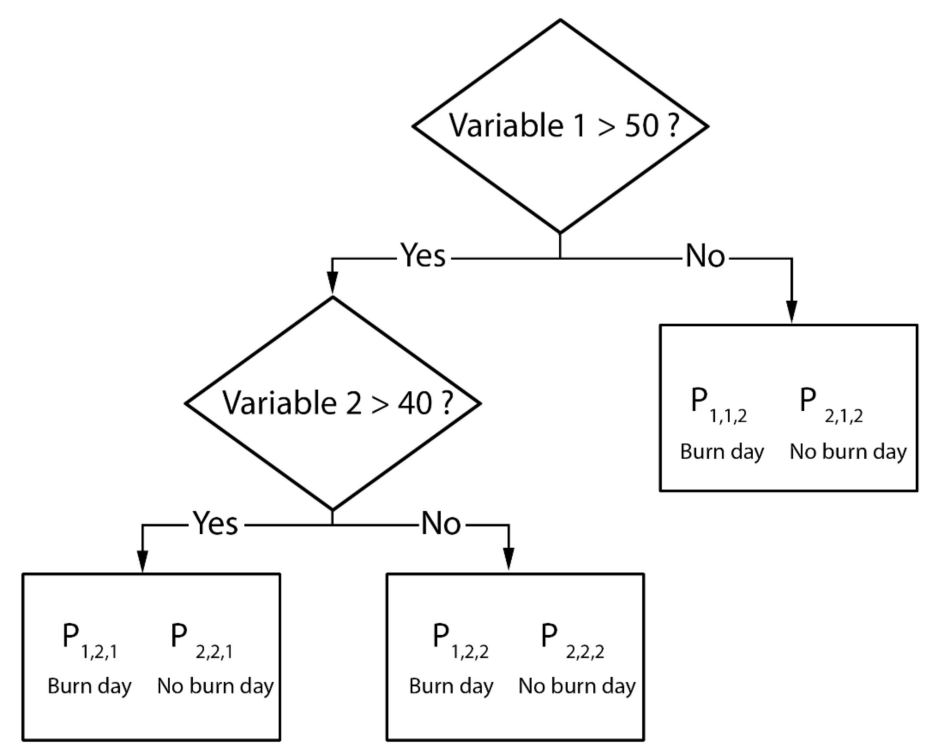

Figure A1. An example decision tree to generate the forecasting probabilities of each class. 


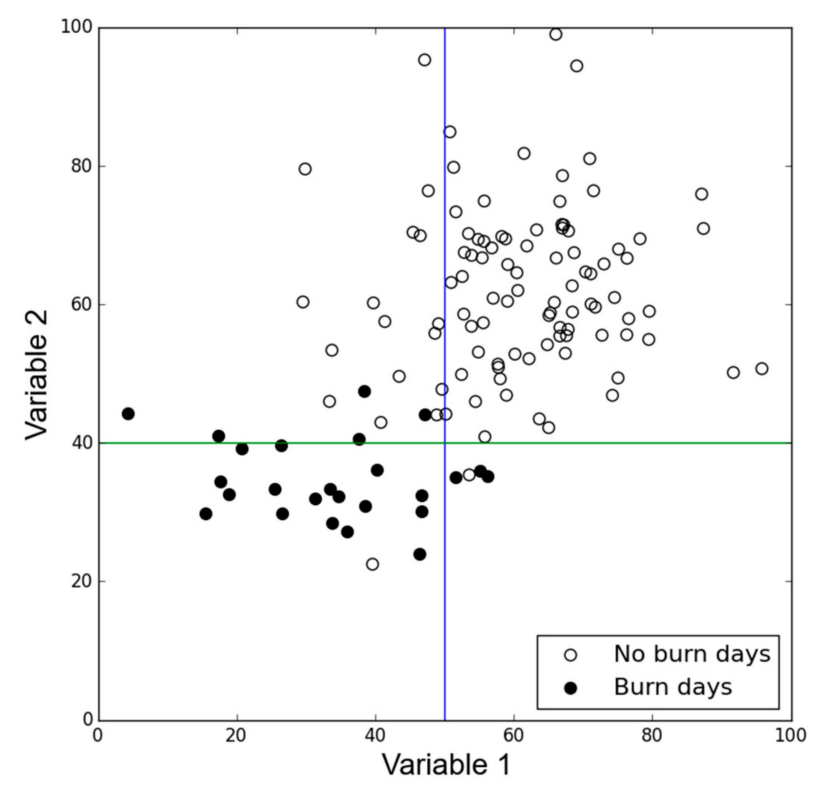

Figure A2. Decision boundaries created by the Classification and Regression Tree (CART) algorithm to classify the data using variable 1 and variable 2 .

The information gain between two nodes is calculated using the information entropy between the nodes, as shown in Figure A3. For simplicity, only the probability index for class is retained in Figure A3.

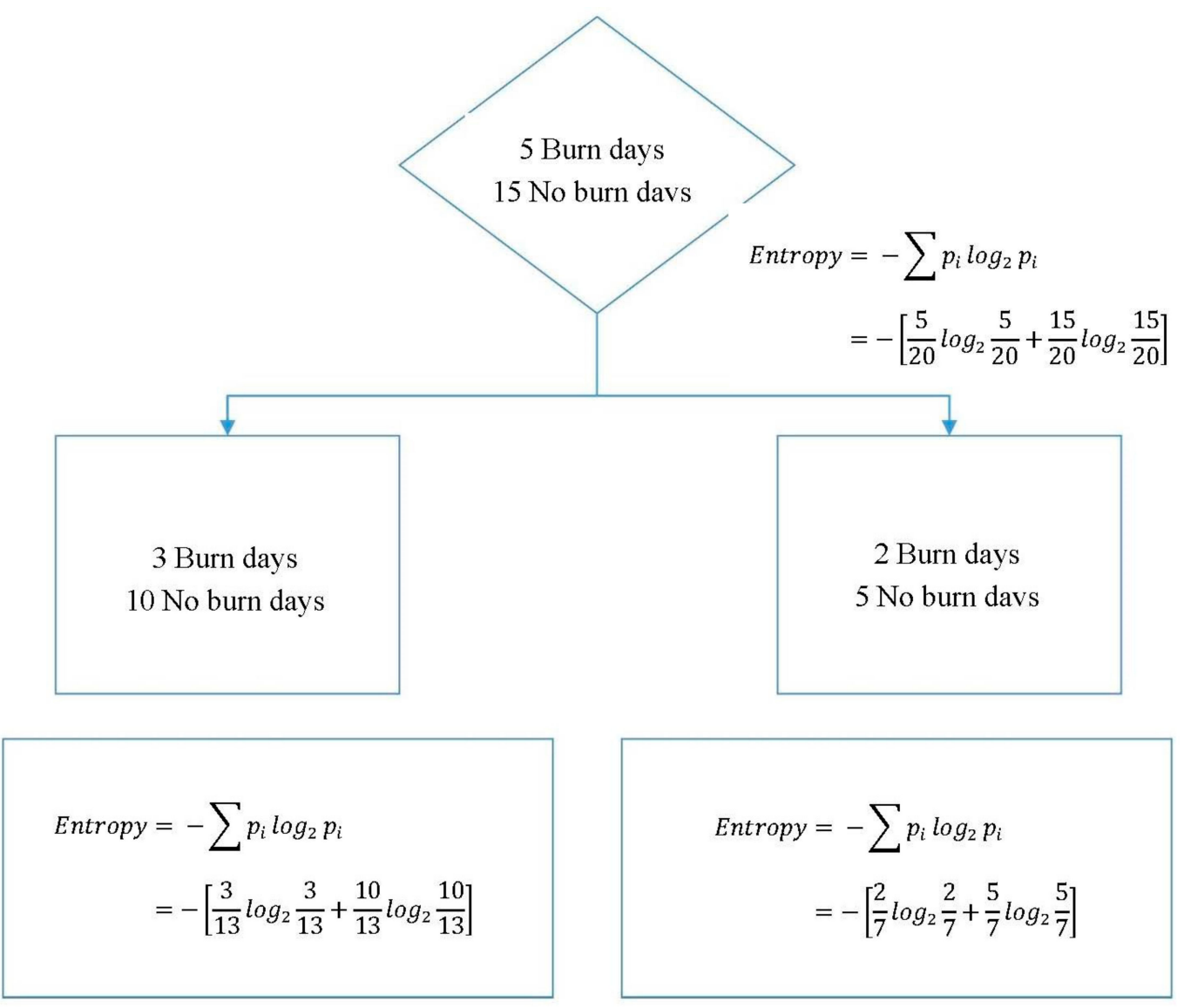

Figure A3. Information gain calculations. 
The information gain, $g$, in this example is equal to

$$
g=0.811-\frac{13}{20} \times 0.719-\frac{7}{20} \times 0.863=0.041
$$

The predictor variable which gives the highest information gain (highest reduction in impurity) is naturally placed at the root node, and this procedure continues recursively to grow the tree.

\section{Appendix C}

Counties in Georgia were grouped in three categories according to their major burners (Figure A4a). Category 1 counties were dominated by a single burner such as the Forest Service (national forests) or Department of Defense (military bases). Category 2 included counties where there are multiple large burners, typically plantations. Finally, Category 3 counties were those where there are no prominent burners. Typical burn sizes of 120,80 , and 40 ha were assigned to these categories.

The average daily burn areas were calculated by dividing the annual or monthly average burn areas for each county by the average annual or monthly number of days with an area of 30 ha or larger permitted to burn (days with smaller permitted burn areas were not considered to be significant burn days) (Figure A4b).

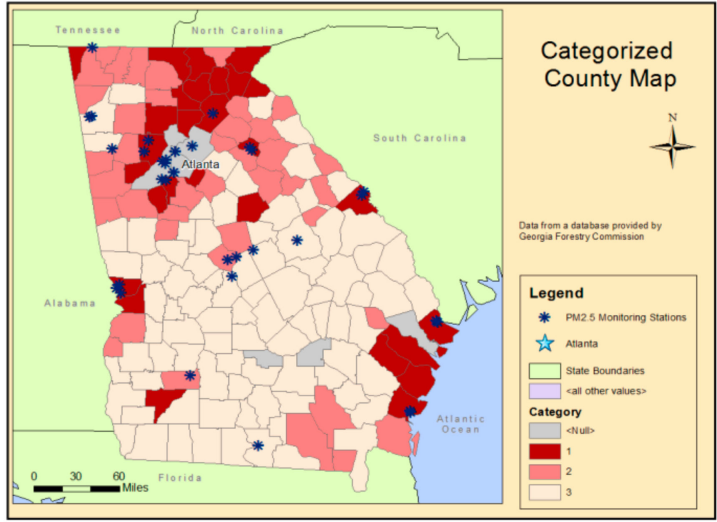

(a)

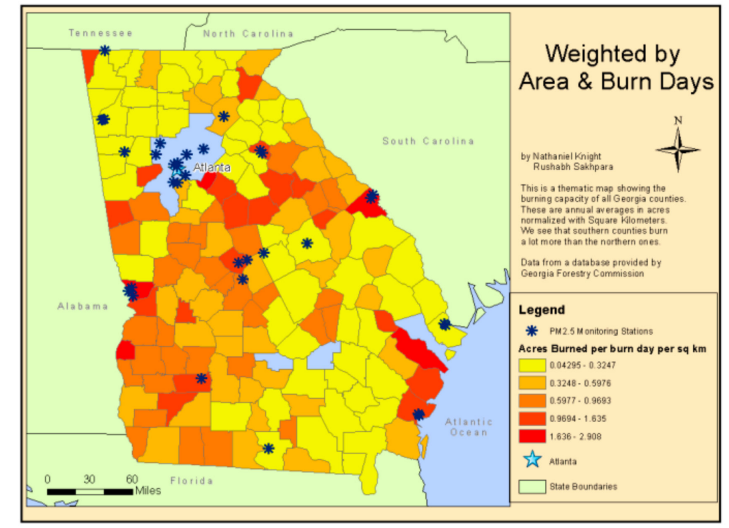

(b)

Figure A4. (a) The type of burners for each county in Georgia as single dominant (Category 1), multiple large (Category 2) and various small burners (Category 3). (b) The average daily burn areas (acres) normalized by the areas of the counties $\left(\mathrm{km}^{2}\right)$.

When a burn day was forecast, the daily burn area was distributed randomly as burns of typical sizes for the burner category throughout the forested areas of the county. The ability to correctly predict the locations of the burns influences the accuracy of the fire impact forecasts at specific air quality receptors [23].

\section{References}

1. Leopold, A. Game Management; Univisity of Wisconsin Press: Madison, WI, USA, 1987.

2. Waldrop, T.A.; van Lear, D.H.; Lloyd, F.T.; Harms, W.R. Long-Term Studies of Prescribed Burning in Loblolly Pine Forests of the Southeastern Coastal Plain; U.S. Forest Service: Washington, DC, USA, 1987.

3. Boddy, J. As record Appalachian wildfires fizzle out, scientists look to learn from the destruction. Science 2016. Available online: http:/ / www.sciencemag.org/news/2016/12/record-appalachian-wildfires-fizzleout-scientists-look-learn-destruction (accessed on 21 December 2016). [CrossRef]

4. Huang, R.; Zhang, X.; Chan, D.; Kondragunta, S.; Russell Armistead, G.; Odman, M.T. Burned Area Comparisons Between Prescribed Burning Permits in Southeastern United States and Two Satellite-Derived Products. J. Geophys. Res. Atmos. 2018, 123, 4746-4757. [CrossRef] 
5. Hu, Y.T.; Odman, M.T.; Chang, M.E.; Jackson, W.; Lee, S.; Edgerton, E.S.; Baumann, K.; Russell, A.G. Simulation of air quality impacts from prescribed fires on an urban area. Environ. Sci. Technol. 2008, 42, 3676-3682. [CrossRef] [PubMed]

6. Rappold, A.G.; Reyes, J.; Pouliot, G.; Cascio, W.E.; Diaz-Sanchez, D. Community Vulnerability to Health Impacts of Wildland Fire Smoke Exposure. Environ. Sci. Technol. 2017, 51, 6674-6682. [CrossRef] [PubMed]

7. Haikerwal, A.; Reisen, F.; Sim, M.R.; Abramson, M.J.; Meyer, C.P.; Johnston, F.H.; Dennekamp, M. Impact of smoke from prescribed burning: Is it a public health concern? J. Air Waste Manag. Assoc. 2015, 65, 592-598. [CrossRef] [PubMed]

8. EPA U.S. 2014 National Emissions Inventory (NEI) Documentation; EPA U.S.: William Jefferson Clinton North, AR, USA, 2014.

9. Liu, Y.; Stanturf, J.; Goodrick, S. Trends in global wildfire potential in a changing climate. For. Ecol. Manag. 2010, 259, 685-697. [CrossRef]

10. Schoennagel, T.; Balch, J.K.; Brenkert-Smith, H.; Dennison, P.E.; Harvey, B.J.; Krawchuk, M.A.; Mietkiewicz, N.; Morgan, P.; Moritz, M.A.; Rasker, R.; et al. Adapt to more wildfire in western North American forests as climate changes. Proc. Natl. Acad. Sci. USA 2017, 114, 4582-4590. [CrossRef] [PubMed]

11. Odman, M.T.; Hu, Y.; Garcia-Menendez, F.; Davis, A.Y.; Chang, M.E.; Russell, A.G. Fires and air quality forecasts: Past, present, and future. EM Mag. 2013, 22, 12-21.

12. Hu, Y.T.; Odman, M.T.; Chang, M.E.; Russell, A.G. Operational forecasting of source impacts for dynamic air quality management. Atmos. Environ. 2015, 116, 320-322. [CrossRef]

13. Lee, P.; McQueen, J.; Stajner, I.; Huang, J.P.; Pan, L.; Tong, D.; Kim, H.; Tang, Y.H.; Kondragunta, S.; Ruminski, M.; et al. NAQFC Developmental Forecast Guidance for Fine Particulate Matter (PM2.5). Weather Forecast. 2017, 32, 343-360. [CrossRef]

14. Odman, M.T.; Boylan, J.W.; Wilkinson, J.G.; Russell, A.G.; Mueller, S.F.; Imhoff, R.E.; Doty, K.G.; Norris, W.B.; McNider, R.T. Integrated modeling for air quality assessment: The Southern Appalachians mountains initiative project. J. De Phys. IV 2002, 12, 211-234.

15. Hu, Y.T.; Chang, M.E.; Russell, A.G.; Odman, M.T. Using synoptic classification to evaluate an operational air quality forecasting system in Atlanta. Atmos. Pollut. Res. 2010, 1, 280-287. [CrossRef]

16. Beaver, S.; Tanrikulu, S.; Palazoglu, A.; Singh, A.; Soong, S.T.; Jia, Y.Q.; Tran, C.; Ainslie, B.; Steyn, D.G. Pattern-Based Evaluation of Coupled Meteorological and Air Quality Models. J. Appl. Meteorol. Clim. 2010, 49, 2077-2091. [CrossRef]

17. Choi, W.; Paulson, S.E.; Casmassi, J.; Winer, A.M. Evaluating meteorological comparability in air quality studies: Classification and regression trees for primary pollutants in California's South Coast Air Basin. Atmos. Environ. 2013, 64, 150-159. [CrossRef]

18. Gass, K.; Klein, M.; Chang, H.H.; Flanders, W.D.; Strickland, M.J. Classification and regression trees for epidemiologic research: An air pollution example. Environ. Health 2014, 13, 17. [CrossRef] [PubMed]

19. Pedregosa, F.; Varoquaux, G.; Gramfort, A.; Michel, V.; Thirion, B.; Grisel, O.; Blondel, M.; Prettenhofer, P.; Weiss, R.; Dubourg, V.; et al. Scikit-learn: Machine Learning in Python. J. Mach. Learn. Res. 2011, 12, 2825-2830.

20. Davis, A.Y.; Ottmar, R.; Liu, Y.Q.; Goodrick, S.; Achtemeier, G.; Gullett, B.; Aurell, J.; Stevens, W.; Greenwald, R.; Hu, Y.T.; et al. Fire emission uncertainties and their effect on smoke dispersion predictions: A case study at Eglin Air Force Base, Florida, USA. Int. J. Wildland Fire 2015, 24, 276-285. [CrossRef]

21. Urbanski, S.P.; Hao, W.M.; Baker, S. Chemical Composition of Wildland Fire Emissions. In Developments in Environmental Science; Bytnerowicz, A., Arbaugh, M., Riebau, A., Andersen, C., Eds.; Elsevier: Amsterdam, The Netherlands, 2009; Volume 8, pp. 79-107.

22. Achtemeier, G.L.; Goodrick, S.A.; Liu, Y.Q.; Garcia-Menendez, F.; Hu, Y.T.; Odman, M.T. Modeling Smoke Plume-Rise and Dispersion from Southern United States Prescribed Burns with Daysmoke. Atmosphere 2011, 2, 358-388. [CrossRef]

23. Garcia-Menendez, F.; Hu, Y.; Odman, M.T. Simulating smoke transport from wildland fires with a regional-scale air quality model: Sensitivity to spatiotemporal allocation of fire emissions. Sci. Total Environ. 2014, 493, 544-553. [CrossRef] [PubMed]

24. Napelenok, S.L.; Cohan, D.S.; Odman, M.T.; Tonse, S. Extension and evaluation of sensitivity analysis capabilities in a photochemical model. Environ. Model. Softw. 2008, 23, 994-999. [CrossRef] 
25. HiRes2 Air Quality \& Source Impacts Forecasting for Georgia. Available online: https: / / forecast.ce.gatech.edu (accessed on 13 April 2018).

26. Hazard Mapping System Fire and Smoke Product by NOAA. Available online: http:/ / www.ospo.noaa.gov / Products/land/hms.html (accessed on 13 April 2018).

27. Lee, J.Y.; Park, C.; Lee, L.M. Identification of a Contaminant Source Location in a River System Using Random Forest Models. Water 2018, 10, 391. [CrossRef]

28. Liu, Y. A Regression Model for Smoke Plume Rise of Prescribed Fires Using Meteorological Conditions. J. Appl. Meteorol. Clim. 2014, 53, 1961-1975. [CrossRef]

29. Breiman, L.; Friedman, J.; Olshen, R.; Stone, C. Classification and Regression Trees; Wadsworth International Group: Belmont, CA, USA, 1984.

(C) 2018 by the authors. Licensee MDPI, Basel, Switzerland. This article is an open access article distributed under the terms and conditions of the Creative Commons Attribution (CC BY) license (http://creativecommons.org/licenses/by/4.0/). 